\title{
Category of opposition in Celtic folk-tales
}

\author{
Nataliya Solovyeva ${ }^{1, *}$ \\ ${ }^{1}$ Moscow State Region University, 10a, Radio Street, 105005, Moscow, Russia
}

\begin{abstract}
A folk-tale narrative with its unique composition and deep-laid semantics is an important phenomenon of modern life. It supplements a rational worldview and preserves its priorities, despite the changes that take place in the technical, informational, communicational and other areas of human activity. The folk-tale model of the world is a binary entity characterized by interconnected oppositions. For this reason the structure of the folk-tale and its holistic perception is largely determined by the category of opposition. The article describes a model for representing the category of opposition in Celtic folklore. The author identifies general and specific types of oppositions and describes the language means expressing them. The proposed methodology for the analysis of the language means makes it possible to go beyond the traditional structural description. It gives an insight into a linguistic opposition as a contextually conditioned or a potential phenomenon. Moreover, the oppositional method can be extrapolated to the study of texts which belong to other genres of literature. Such research contributes to the understanding of British ethnic mentality. Establishing what is seen as the opposite in the texts of traditional folk culture helps to identify cultural meanings in language units.
\end{abstract}

\section{Introduction}

Binary oppositions systematize abstract concepts and ideas by arranging them into pairs, such as life and death, truth and lies, presence and absence, profane and spiritual, etc. Therefore, the system of binary oppositions is one of many systems that enables a human's mind to comprehend meaning of concepts and ideas [1]. The problem of contrasted language units has its origins in the structuralism theory. According to Ferdinand de Saussure, the binary opposition is the "means by which the units of language have value or meaning; each unit is defined against what it is not" [2]. In the first place, opposition is a paradigmatic relationship between language units that have differential attributes in a given language [3]. One thing can be distinguished from another thing only when it is contrasted with or opposed to something else.

\subsection{Phonological oppositions}

A phoneme is the smallest contrastive unit in the sound system of a language [4]. Phonological, or phonologically distinctive, oppositions are those of sounds which are

\footnotetext{
*Corresponding author: natavs@list.ru
} 
capable of differentiating the lexical meaning of two words in a particular language, e.g. pat - bat [5]. It is necessary to mention that an opposition not only presupposes the properties by which the opposition members are distinguished, but also the properties that are common to both of them, i.e. the basis for comparison [5].

Phonological oppositions are classified according to three aspects: their relationship to the entire system of oppositions (bilateral and multilateral oppositions), the relation between opposition members (privative, gradual and equipollent oppositions), and the extent of their distinctive force (constant and neutralizable oppositions).

\subsection{Grammatical oppositions}

Phonological principles manifested in structuralism can be applied to the description of grammatical oppositions. Relations between members of a grammatical opposition are based on the principle of markedness / unmarkedness: one of the members of the opposition expresses a certain property and is marked, while the other member of the opposition leaves the property unexpressed and is unmarked [6].

The same as phonological oppositions, grammatical oppositions can be privative, gradual and equipollent. Members of equipollent oppositions are opposed on the basis of their grammatical meaning, and members of privative oppositions are opposed on the basis of their derivational meaning [7].

\subsection{Lexical oppositions}

E. Coseriu transferred the oppositional method to the field of semantics [8] and pointed out three types of oppositions: privative oppositions which are formed between a member that possesses a specific semantic property and a member that does not possess it, e.g. animate - inanimate; gradual oppositions whose members possess different values of a certain semantic property, e.g. hot - cold; equipollent oppositions which are formed between two terms, each of them possessing a positive differentiating property, e.g. male-female.

The concept of opposition is distinguished from the concepts of complementarity and converseness [9-11]. Thus, the term "opposition" is used in the most general sense. Members of gradual oppositions are antonyms, because their meanings express the polar manifestations of a property, e.g. long - short. Members of non-gradual oppositions are defined as complementaries, since each of the members of the opposition is characterized by the presence of a property, e.g. dead-alive. Converses describe the same situation from the perspective of its different participants, e.g. buy - sell, doctor-patient, above - below [10].

\subsection{Syntactic oppositions}

Conclusions obtained from the observation of the category of opposition at the phonological, morphological and semantic levels can be extended to the syntactic level. A. Mettinger draws on the Saussurian distinction between the abstract language system and language in use. It is established that there are contextual or syntagmatic frames which favour the application of opposites [12]. Mettinger's ideas are developed by M. Davies, who elaborates on the classification of syntactic frames and the way they might trigger contextual oppositions. There are negated, transitional, comparative, replacive, concessive, explicit and contrastive oppositions, ancillary antonymy and parallelism [13]. 


\subsection{Textual oppositions}

The category of opposition permeates all levels of the language and represents a "vertical" hierarchy of different types of oppositions. However, at the text level it makes sense to speak about contrast that is linguistically revealed via oppositions of the phonetic, morphological, semantic and syntactic levels. "Contrast establishes a hierarchy of multilevel elements within the text, it highlights the features of difference, oppositeness" [14]. Contrast-sensitive units are divided into real and potential [15]. The real ones are those which are able to form oppositional relationships autonomously. Potential ones are occasional or contextual opposites that can express contrast within a particular speech situation.

Although the language units that express the category of opposition in English have been thoroughly studied, the question still remains concerning the role of opposites of different language levels in providing coherence and integrity of the entire text and its individual segments. Another matter worth discussing is whether potential opposites share the same status as the usual opposites with regard to the linguistic system of English.

\section{Methods}

To establish the types of potential opposites and to identify their role in providing coherence and integrity of the entire text we developed a model for representing the category of opposition in folk-tale discourse and studied the multi-level language means that serve to express it.

The study material is represented by the corpus of texts in English, namely 189 folktales included in the folk-tale collections "Folk Tales of the British Isles" [16], "Irish Fairy Tales" [17], "Celtic Fairy Tales" [18], "Irish Fairy Tales" [19], "Irish Folk \& Fairy Tales" [20], "Welsh Folk Tales" [21], "The Book of Fairy and Folk Tales of Ireland" [22]. Using the continuous sampling method, we extracted contexts with oppositions from the texts of folk- tales.

Having applied a systemic method that allowed us to consider folk-tale discourse as a systemic phenomenon, in the interdependence of all its levels and units, and the method of contextual and componential analysis, we created a model for representing the category of opposition in folk-tale discourse.

The structure of a folk-tale and its holistic perception are largely determined by the categories of space and time. The defining feature of a folk-tale as a genre is its fictional character. Its anthropocentricity reveals itself in the fact that a hero of non-magical nature, who encounters obstacles, overcomes them and learns lessons, is placed in the centre of the folk-tale worldview. Thus, the category of opposition in the folk-tale discourse is represented by three general oppositions: spatial-temporal opposition, the opposition of non-magical characters (people) and the opposition of the magical versus the non-magical (Figure 1). 


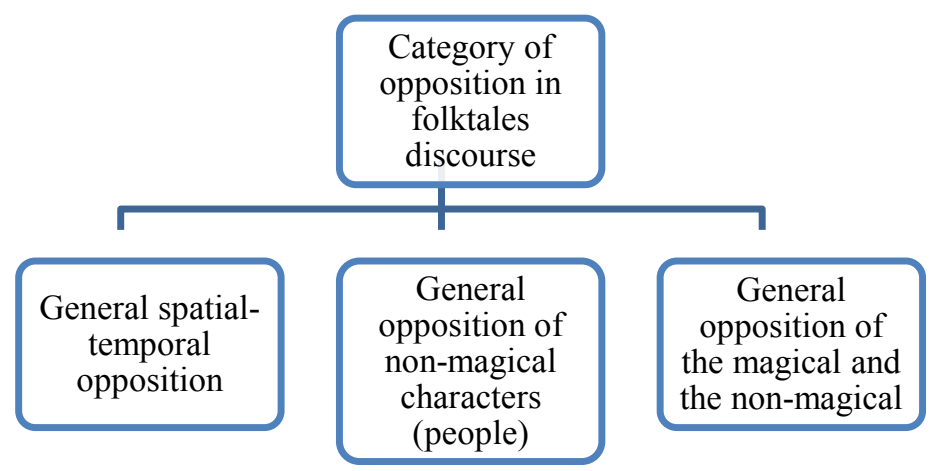

Fig. 1. General oppositions in folk-tale discourse.

General oppositions are inherent in the whole class of objects or phenomena. Spatialtemporal oppositions, oppositions of non-magical characters (people) and oppositions, in which the "magical" and the "non-magical" are opposed, are seen as general. Specific oppositions bring forward the differential properties of opposed objects or phenomena and serve to distinguish between representatives of the same class. Further the results of the general oppositions analysis are demonstrated.

The general spatial-temporal opposition, which serves to ensure logical consistency, temporal and spatial interconnection of text elements, includes six subtypes of oppositions: in the order of events and things, in terms of time periods, in the direction of movement in space, in the position in space, in the frequency of actions and events, and in the duration of actions and events. General spatial-temporal oppositions are found in 30,3\% of the analyzed contexts.

The folk-tale, despite the significant role of the fictional element, is largely anthropocentric. Therefore, it seems reasonable to single out the general opposition of nonmagical characters (people). Within the general opposition of non-magical characters (comprising $35,8 \%$ of contexts out of the total number of samples), two subtypes of oppositions are found: the opposition of two non-magical characters, expressing social conflict, and the opposition of the changing status and actions of one non-magical character, expressing internal, individual conflict.

The results of the analysis of the general opposition of the magical versus the nonmagical (represented in $33,9 \%$ of contexts) allowed us to identify six subtypes: the opposition of natural facts (a natural fact is a natural phenomenon or a floristic object with a magical property); the opposition of artifacts (an artifact is an object possessing magical or anthropomorphic properties); the opposition of magical creatures similar to people or not having similarities in the real world; the opposition of a person and a magical creature; the opposition of a person and a magical animal capable of changing shapes or performing human activities; the opposition of two magical animals. All the singled out subtypes are shown below (Figure 2). 

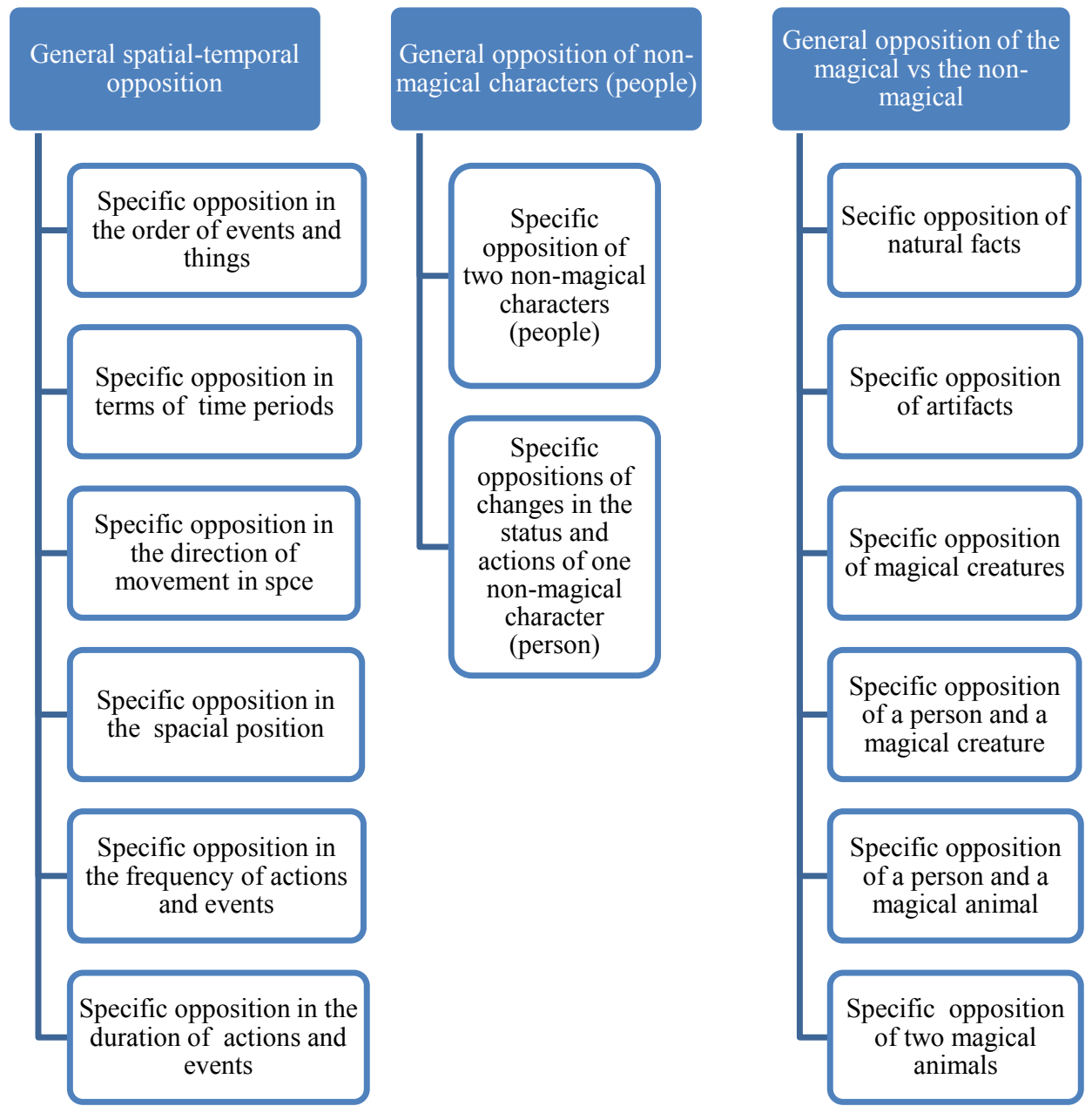

Fig. 2. Specific oppositions in folk-tale discourse.

Having applied the oppositional method to analyze the category of opposition at the morphological, lexical, lexical-phraseological, syntactic, dictum, hyper-dictum levels, we have come to the conclsion that the general and specific types of oppositions in folk-tale discourse are expressed by means of usual, contextually determined and potential opposites. We have also identified the prevailing groups of opposites for each type of oppositions.

\section{Results}

A study of the language means expressing oppositions in Celtic folk-tales made it possible to point out a number of groups.

The first group includes usual lexical oppositions (32,1\% contexts): "So the mother arose and baked not one cake but two, a big one and a little one" [17].

The second group comprises oppositions of different levels which include:

- oppositions of different parts of speech (2,6\% contexts), e.g. "Soon after the birth of the daughter the husband died" [Ibidem]; 
- lexical-phraseological oppositions ( $2 \%$ contexts), e.g."...on the moment the horse rose under him... and came down in Erin" [Ibidem].

It is human nature to think in opposites, to characterize one's experience from polar points of view, but this contrast can be different from the contrasts typical of a culture, social or age group to which a person belongs. In this case, the opposition is the result of a person's linguistic creativity that does not have a universal character. Since the material of this study is folk-tale texts, which were originally passed on from generation to generation orally, it means contextual oppositions are largely due to the tale-teller's linguistic creativity. The context is organized in such a way that linguistic units, the semantic structure of which includes peripheral contrast-generating semes, are opposed. Contextual oppositions, which belong to the third group, include:

- language units whose meanings are contrasted due to the presence of peripheral oppositional semes in their meanings (9,3\% contexts). Thus, in the following example the lexemes master and journeyman are opposed in the meaning of a chief and a subordinate, e.g. "...we'll see who is to be the master, and who the journeyman" [Ibidem];

- associatively related language units which are contrasted in a context due to the concomitant syntactic oppositions (7,2\% contexts), e.g. "He had neither prayers nor catechism no more nor the others" [Ibidem];

- synonymous language units contrasted in an antonymous context (3,5\% contexts). For example, the synonyms burned and scalded are opposed in the context with the negative particle and the conjunction nor: "a bottle of green ointment, that wouldn't let you be burned, nor scalded" [22].

The forth group comprises oppositions represented by language units whose semantic structure includes potential contrast-forming semes which become relevant in a specifically organized context (11,9\% contexts). The lexemes courage and despair become opposed in the context with the adverb instead: Last of all, difficulties gave you courage, instead of lending you despair" [17].

The fifth group includes grammatical oppositions which are formed by means of:

- correlating antonymous morphemes (5,8\% contexts). There are cases in which root morphemes are opposed, e.g. "They took the bed in the left-hand room...so they took the bed in the right-hand room" [Ibidem]. In other cases an opposition is made up by the a negative and a zero morphemes, e.g. "Oh, every place likely and unlikely for them all to be in" [Ibidem];

- verb forms which express the opposition of tenses (2,8\% contexts), e.g. And as they had sat that time twelvemonth, so sat they that night" [Ibidem];

- functional words which express the opposition within a sentence (3,2\% contexts), e.g. "I am no sooner up than down" [Ibidem];

- voice forms reflecting the opposition of an action performed by the subject and an action the object undergoes (1,8\% contexts), e.g. "Well, he couldn't imagine who threw it at him, or why it was thrown at him" [17];

- mood forms that convey a contrast between real and possible or probable situations $(1,2 \%$ contexts), e.g. "But no husband would I have...neither will I yet have one unless thou reject me" [Ibidem].

Finally, the sixth group comprises syntactic oppositions which are formed due to:

- a negative particle or a negative adverb in one of the opposed syntactic constructions ( $8,9 \%$ contexts), e.g. "Day came, and the loch did not go out. But... when the sun was rising out of the water the loch went out" [Ibidem];

- opposed mood forms in the syntactic constructions $(2,1 \%$ contexts), e.g. "The man became quite angry and swore they could not be his children. The woman cried just as angrily that they were" [22]; 
- the opposed subject and object in the syntactic constructions $(1,4 \%$ contexts $)$, e.g. "Never had prince such a subject"..."Never had subject such a prince" [21];

- functional words which serve to oppose two syntactic constructions (3,1\% contexts), e.g.

"Jack, honey, what will I do with you? Or what will I do without you?" [Ibidem];

- verbs with negative semantics (fail, refuse) in one of the opposed constructions $(1,1 \%$ contexts), e.g. "They searched every spot in the place. Still they failed to find him ..." [Ibidem].

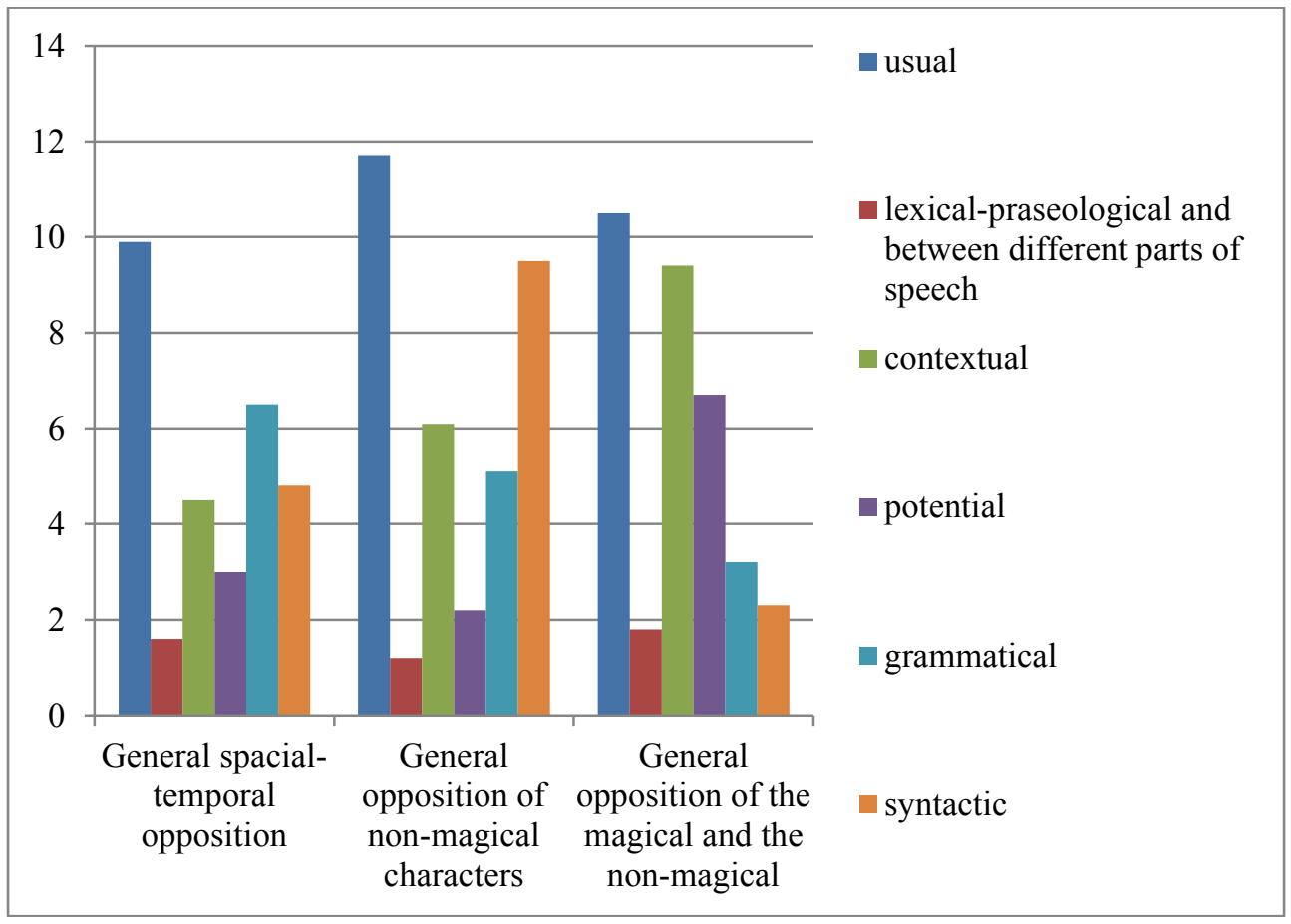

Fig. 3. Correlation of language means to express general oppositions in folk-tales.

The undertaken analysis allows us to state that the number of oppositions formed due to the presence of peripheral or potential contrast-forming semes in the meaning of language units is almost equal to the number of usual oppositions ( $31,9 \%$ and $32,1 \%$ respectively). Thus, context plays a crucial role in expressing oppositions.

Relations between the opposed units can be revealed through a dictum - the thematic unit of a text, represented by a sentence or a group of sentences and forming the level of language that follows the sentence level [23]. Oppositions of various types are involved in the construction of the compositional and semantic unity of a dictum. There are five possible arrangements of opposites within a dictum:

- the end-to-end arrangement of the opposites, which serves to contrast the properties in a consecutive way;

- the concentrated arrangement of the opposites, in which the opposition is represented in two sentences in a row - the semantic center of the dictum;

- the arrangement of the opposites at the beginning of the dictum, which serves as a kind of prologue to the subsequent narrative;

- the arrangement of the opposites at the end of the dictum, which serves as a logical conclusion to the narrative;

- the arrangement of one of the opposition members at the beginning, and the other - at the end of the dictum, which serves to describe how the character or the situation changed [24]. 
Further the most common arrangements of opposites in Celtic folk-tales are described.

Opposites can be placed in contact as part of one sentence included in the dictum. In this case, they are likely to oppose the characters' features or the features of the setting in which the events unfold. Despite the contact arrangement, they usually serve as a means of semantic connection between sentences that form a dictum, as the members of the opposition are usually mentioned in the previous or subsequent sentences.

There are several types of contexts within the framework of a single dictum, the most common ones being:

- the type of context in which the presence of one property is excluded and the presence of another property is emphasized. The opposites are connected with the conjunction but: "He was as gentle as $a$ lamb at home but $a$ lion in the chase" [17].

- the type of context which implies the mutual exclusion of opposites and contains the negative particle not or the conjunction neither... nor: “...let neither man nor creature kiss you..." [Ibidem].

- the type of context which implies the alternative relations between the opposites which are connected by the conjunctions or, either...or: "... whether he should be there all that time or should only be on land for an hour by the clock" [Ibidem]. The conjunction either...or fetches out the contrast more distinctly: “... there was no one, either natural or supernatural..." [22].

- the type of context in which the opposites complement each other and are connected with the help of the conjunctions and, both...and, integrating two opposed properties into a single whole: "I'll bring you away... and I'll bring you back to her the same way" [17]. The opposition is represented by the phrasal verbs which express reverse directions.

- the type of context in which the opposites are connected asyndetically serves to depict a quick change of opposed properties and make the description more dynamic: "The eldest two were...; the youngest never did much..." [Ibidem].

As the analysis reveals, the arrangement of the opposites in the dictum can be distant as well. Opposites can be placed in different sentences and serve as semantic centres of the opposed segments within the dictum: “...... a foal and its mother feeding there, both as fat as. .. a foal and its mother, so lean that..." [17]. In addition, oppositions also play the role of an integrating element within the framework of a dialogical dictum. The meaning of affirmative and negative remarks would be unclear outside the antonymous context, e.g "You put salt in the pot..." - "I did not, mother." - "You did..." [17].

Opposition can be formed not only within the limits of one dictum, but also wider, within the hyper-dictum, uniting several dictums. The oppositions arranged in different dictums within a hyper-dictum, as a rule, are linked thematically and characterize spatial and temporal connections. The entire text can be organized following the principle of contrast. In this case, the meaning of opposition is revealed due to the usual, contextual and potential oppositions of different language levels.

\section{Discussion}

Referring to texts, we prefer to use the term "opposite" to denote all types of opposed units, since it does not impose restrictions on the type of expressed opposition (antonyms, complementaries and converses can be called opposites), the means of expression (pairs of opposites can be represented by morphemes, lexemes, phraseological units, sentences, etc.) and the conventionality of opposition (opposites can be usual, contextual, potential).

Since the context plays a decisive role in creating oppositions, we suggest a typology of antonymous contexts, including 18 types represented in Celtic folk-tales. Here belong the following types:

1) the contexts within the limits of a sentence: 
- the context in which the opposites complement each other to a single whole and are connected by the conjunction and;

- the context in which the opposites are connected by the conjunction but, with one property being denied and the other emphasized;

- the context in which the opposites are excluded and connected by the conjunctions neither...nor or the negative particle not and the conjunction nor;

- the context in which the opposites are seen as alternatives and connected by the conjunctions or, either...or;

- the context in which the opposites are connected asyndetically, providing for the dynamic change of the opposed properties;

- the context in which the opposites are used with the prepositions from...to marking the spatial or temporal borders;

- the context in which the opposites are compared and connected with the conjunction than;

- the context with the temporal conjunctions while and when;

- the context with the adverb as which implies similarity of the opposites in some aspect;

- the context with the preposition after in which the opposites are arranged in order, one after the other;

- the context with one member of the opposition being the subject and the other being the object in the sentence;

- the context with the adverb instead, the members of the opposition replacing one another;

- the context with the conditional conjunction if;

- the context with the conjunction although indicating concession;

2) the contexts within the limits of a dictum:

- the context with the opposition members in two consecutive sentences forming the semantic centre of the dictum;

- the context with the opposition members in the first and in the final sentences of a dictum forming the semantic frame;

$3)$ the contexts within the limits of a hyper-dictum:

- the context with the opposition members in two consecutive dictums forming the semantic centre of the hyper-dictum;

- the context with the opposition members at the beginning and the ending of a folk-tale forming the temporal frame within which the story unfolds.

The study made it possible to establish a specific feature of folk-tale discourse - the density of different types of oppositions in a context. Thus, one context may contain a few specific oppositions which belong to one general opposition or a few oppositions which belong to different types of general oppositions. For example, in the following context the spatial grammatical opposition represented by the prepositions before - behind is combined with the grammatical opposition of the magical and non-magical characters' actions: "The cold winter's wind that was before them, they overtook her, and the cold winter's wind that was behind them, she did not overtake them" [17]. 


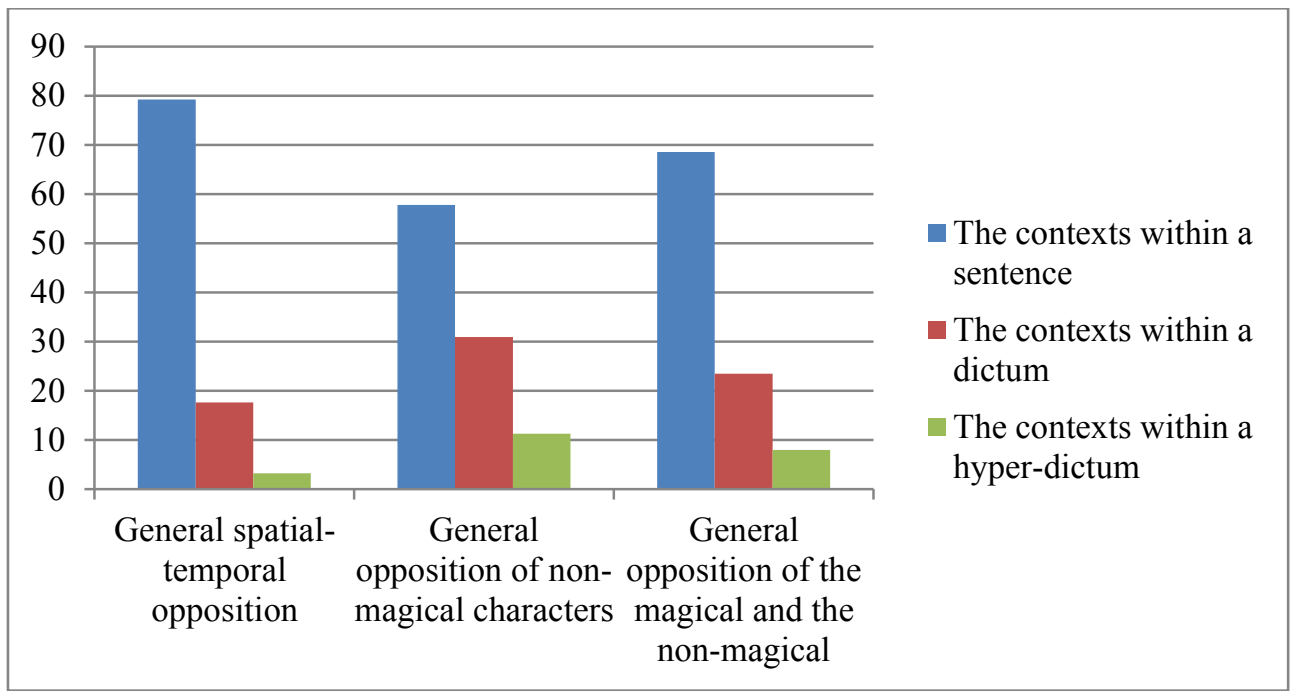

Fig. 4. Correlation of contexts in which general oppositions are represented.

Having studied the relevance of various contexts types, we identified the most significant ones for each of the general types of folk-tale oppositions. Thus, the general spatialtemporal opposition is expressed mainly in contexts with the conjunction and $37,8 \%$ of spatial-temporal oppositions), in different sentences within the same dictum $(17,6 \%$ of the spatial-temporal oppositions) and in contexts with asyndetic connection (14,2\% of the spatial-temporal oppositions). Obviously, opposed spatial and temporal characteristics are considered not as mutually exclusive, but rather as complementing each other, and their close arrangement helps to enhance the contrast between them. The number of spatialtemporal oppositions, whose members are located in different dictums, is small $(3,2 \%)$, therefore, they are less likely to contribute to the text cohesion.

The general opposition of the magical versus the non-magical is usually represented in contexts with the conjunction and $(23,8 \%$ of the oppositions of the magical and nonmagical), in different sentences within the same dictum $(23,5 \%$ of oppositions of the magical and non-magical) and contexts with the conjunctions or / whether ... or / either ... or, involving a choice between two opposites (13,4\% of oppositions of the magical and non-magical). The number of oppositions, whose members are located in different dictums, is considerably higher $(8 \%)$, which proves their role in ensuring cohesion at the text level.

The general opposition of non-magical characters (people) is also often expressed in contexts with the conjunction and (22,8\% of the oppositions of non-magical characters), in contexts with asyndetic connection (14,2\% of the oppositions of non-magical characters) and in different sentences within the same dictum (30,9\% of the oppositions of non-magical characters). The role of the general opposition of non-magical characters (people) in ensuring text cohesion is slightly more important than that of the general opposition of the magical and the non-magical $(11,3 \%)$.

The analysis of the contexts also made it possible to draw some conclusions concerning the Celtic folk-tale worldview. First of all, the mythological pre-logical way of thinking is retained in the spatial and temporal oppositions. Their members are considered not as mutually exclusive, but rather as complementing each other, which is demonstrated by their contact arrangement and coordinative connection between them. Secondly, beliefs in the supernatural forces, whicht used to guide a person's life in the past, are revealed in the oppositions of the magical creatures and people, the former acting as the subject and the latter as the object of the action. Even so, a person stays the centre of the folk-tale 
worldview as the oppositional relations between the magical creatures and animals are modeled upon those between people. Finally, the magical and the non-magical are seen as complementary elements in the Celtic folklore, which is proved by the corresponding oppositions represented in the contexts with coordinative conjunctions.

\section{Conclusion}

The proposed methodology for analyzing the category of opposition exposes the opposition as a usual, contextual or potentially possible phenomenon. The text is a prerequisite for the manifestation of the essential features of opposed units, since the semantic meaning of opposition is realized by them in contact use in a certain environment. We emphasize that the opposition, in turn, plays a significant role in ensuring cohesion and coherence of the text, maintaining its linear internal organization and explaining the logical and sense connections in the text.

The oppositional method can be implemented for the analysis in other types of discourse but it is applicable primarily to texts of other folklore genres. Regarding the prospects of using the method to study the implementation of other categories, it is possible to study the category of cohesion, which is among the mandatory categories of any text and serves to ensure its semantic integrity. The opposites provide antonymic cohesion, i.e. connectedness at the level of the form, which in turn leads to coherence, i.e. connectedness at the level of the content.

\section{References}

1. A. Putri, P. Sarwato, Journal of Language and Literature 16(01), 82 (2016)

2. The literary https://www.litencyc.com/php/stopics.php?rec=true\&UID=122

encyclopedia,

3. P.H. Matthews, The concise Oxford dictionary of linguistics (Oxford, Oxford University Press, 1997)

4. D.A. Burquest, Phonological analysis: A functional approach (Dallas, TX, SIL International Publications, 2006)

5. N.S. Trubetzkoy, Principles of phonology (Berkeley and Los Angeles, University of California Press, 1971)

6. R.O. Jakobson, Selected works (Moscow, Progress, 1985)

7. V.A. Plungyan, General morphology: Introduction (Moscow, Editorial URSS, 2003)

8. E. Coseriu, H. Geckeler, Trends in structural semantics (Tübingen, Narr, 1981)

9. A. Cruse, Meaning in language: an introduction to semantics and pragmatics (Oxford, Oxford University Press, 2011)

10. J. Lyons, Linguistic Semantics (Cambridge, Cambridge University Press, 1995)

11. L.M. Murphy, Semantic relations and the lexicon: antonymy, synonymy and other paradigms (Cambridge, Cambridge University Press, 2003)

12. A. Mettinger, Aspects of semantic opposition in English (Oxford, Oxford University Press, 1994)

13. M. Davies, Oppositions and ideology in news discourse (London, Bloomsbury, 2012)

14. L.P. Poznyak, Magister Dixit 2(14), 25 (2014)

15. A.V. Kuleshova, Izvestia VSPU 2(87), 4 (2014)

16. J. Riordan, Folktales of the British Isles (Moscow, Raduga Publishers, 1987) 
17. J. Jacobs, Irish fairy tales (London, Wordsworth, 2011)

18. J. Jacobs, Celtic fairy tales (London, Dover Publications, 1968)

19. P. O'Farrell, Irish fairy tales (Dublin, Gill\& Macmillan, 2017)

20. M. Scott, Irish folk \& fairy tales (London, Sphere Books, 2013)

21. P. Stevenson, Welsh folk tales (London, The History Press, 2017)

22. W.B. Yeats, The book of fairy and folk tales of Ireland (London, Bounty Books, 2016)

23. M.Ya. Bloch, Theoretical foundations of grammar (Moscow, Vysshaya shkola, 2004)

24. N.B. Boeva-Omelechko, Lexical, grammatical and textual antonyms in modern English and Russian (Rostov-on-Don, IPO PI SFU, 2013) 